\title{
Etiology and Management of Complete Acute Urinary Retention in Urology Department in N’Djamena, Chad
}

\author{
Kimassoum Rimtebaye ${ }^{1 *}$, Edouard Hervé Moby Mpah"2, Arya Zarif Agah Tashkand1, \\ Franklin Danki Sillong3, Mignagnal Kaboro', Lamine Niang4, \\ Serigne Magueye Gueye ${ }^{4}$
}

${ }^{1}$ National General Referal Hospital of N'Djamena, N’Djamena, Chad

${ }^{2}$ Laquintinie Hospital of Douala, Douala, Cameroon

${ }^{3}$ Protestant Hospital of N'Gaoundéré, N'Gaoundéré, Cameroon

${ }^{4}$ Grand Yoff General Hospital of Dakar, Dakar, Senegal

Email: *melinarim@yahoo.fr

How to cite this paper: Rimtebaye, K., Mpah, E.H.M., Tashkand, A.Z.A., Sillong, F.D., Kaboro, M., Niang, L. and Gueye, S.M. (2017) Etiology and Management of Complete Acute Urinary Retention in Urology Department in N'Djamena, Chad. Open Journal of Urology, 7, 16-21. http://dx.doi.org/10.4236/oju.2017.71003

Received: November 25, 2016

Accepted: January 9, 2017

Published: January 12, 2017

Copyright $\odot 2017$ by authors and Scientific Research Publishing Inc. This work is licensed under the Creative Commons Attribution International License (CC BY 4.0).

http://creativecommons.org/licenses/by/4.0/

c) (i) Open Access

\begin{abstract}
Goal: To study the epidemiological, clinical, etiological, characteristics and ensure earlier management of complete acute urine retention (CAUR) in the urology department of N'Djamena in Chad. Patient and Method: It was a retrospective descriptive study of a sample of 606 patients during the period ranging from November 2008 to December 2010. The patients were consulted first in urology or referred by a colleague for a CAUR. The diagnosis was confirmed by an earlier clinical examination. The patients have benefited from a urine evacuation before looking for the etiologies. Results: We managed a sample of 606 patients suffering from CAUR. Average age was 60 years old with extremes of 1 month and 100 years. There were more patients in the ranks of 60 years and more $(n=436 ; 71.94 \%)$. Men were more than women in the proportion of $583 / 25$, and $63.20 \%$ of the patients lived In N'Djamena. The benign prostatic hypertrophia was the first cause of CAUR, followed by urethral stricture, urinary infection, lithiasis of the lower urinary tract, adenocarcinoma of the bladder, hymen imperforation in young girls, bilharzias, paraphimosis and ovenbird necrosis. The bladder catheterization was the most urgent gesture done in $61.71 \%$, followed by open cystostomy. In the second case, etiological treatment was done as: open prostatic surgery $(\mathrm{n}=$ 306), urethral reconstitution $(n=58)$, cystololithotomia $(n=54)$, dilatation of urethral conduct $(n=54)$, hymenostomia $(n=6)$. Conclusion: CAUR was the first symptom which motivated the consultation in the department of urology in N'Djamena the main problem of public health in Chad.
\end{abstract}




\section{Keywords}

CAUR, Prostrate, Urethra, Lithiasis, Bilharziasis, Catheterization

\section{Introduction}

If urination for animals among other things allows them to mark their territory, for man it is a behavior of survival. Indeed, no pee for 24 hours, runs for humans the risk of death. The Complete Acute Urinary Retention (CAUR) is the impossibility to bring out (withdraw) urine from the bladder through the urethral conduct in spite of the need of urination [1] [2] [3] [4]. It is the most urgent situation to attend to in urology which requires an urgent solution to solve before looking for an etiology. According to the French urologist Félix Guyon (21 Juillet 1831-20 Juillet 1920), the CAUR means "pisser oumourir" (Urinate or die) because at this point in time, the patient asks his doctor just to help him bring out the urine if not he will die. Men suffered more from this illness than women because the urinary conduct of men is longer than women's which exposes them to more dangers.

Sonography (ultrasound), X-Ray, urological endoscopy had an incommensurable role to point out the etiological diagnostic [5]. The etiologies were often: Benign Prostate Hyperplasia ( $\mathrm{BPH})$, urethral stricture, lithiasis, urinary infection. Emergency management is only during the earlier evacuation of urine but etiological management is important, it depends on its causes. Some cases like $\mathrm{BPH}$ and urethral stricture benefited from the mini-invasive treatment by urological endoscopy.

The main aim of this study is to determine the epidemiological, etiological aspects and the management of CAUR in the urological department.

\section{Patients and Methods}

It was a retrospective and descriptive study about a sample of 606 patients during the period from November 2008 to October 2010 about the patients who firstly were consulted in the urology department and those who were referred by colleagues. The patients who benefited from the management and follow up in the urology were included. Patients who had some mistakes in their medical records (incomplete folder, lost of sight, etiologic treatment administered in another department) and those who were managed in other hospitals were excluded. The variables studied were: socio demographics (frequency, age, sex, residence, single, married), clinical and paraclinical (antecedence, general state of wealth, data of rectal touch, blood test, urinary test, X-Ray and sonography), therapy (urgency therapy, etiology treatment), evolution (normal micturition, complication and death). Patients were followed up every 3 months for one year. Before beginning the study, we obtained the authorization: from the Dean of the faculty of health sciences in the university of N'Djamena in Chad, from the national 
committee of ethics, from the director of HGRN and from the head of the urology department. We had also obtained the permission from the patients before including them in the study and using the pictures only for illustration in order to improve scientific research.

\section{Results}

The CAUR represented $62.28 \%$ (Figure 1) of consultation motives in the department of urology in N'Djamena. The range of patients, who were aged 60 years and above, was increased. The average age was 60 with the extremes of 1 month and 100 years. Men had suffered more than women with sex ratio of $581 / 25$. The male predominance is equal to the sex ratio which is 581/25. Etiologies of the CAUR are many and various with two particularities: a urethral abscess (Figure $2 \&$ Figure 3 ) and 6 cases of hymen imperforation. The etiologies of the CAUR were different and numerous: BHP $(\mathrm{n}=218)$, adenocarcinoma of prostate $(n=19)$, bladder urothelialtumor $(n=17)$, urethral stricture $(n=41)$, urine infections $(n=30)$, bladder or urethral lithiasis $(n=30)$, urethral trauma $(n=19)$, prostate infection $(n=7)$, Hymen imperforation $(n=6)$, Cesarean (may be anesthesia medications). Urine analysis brought out 30 cases of infections.

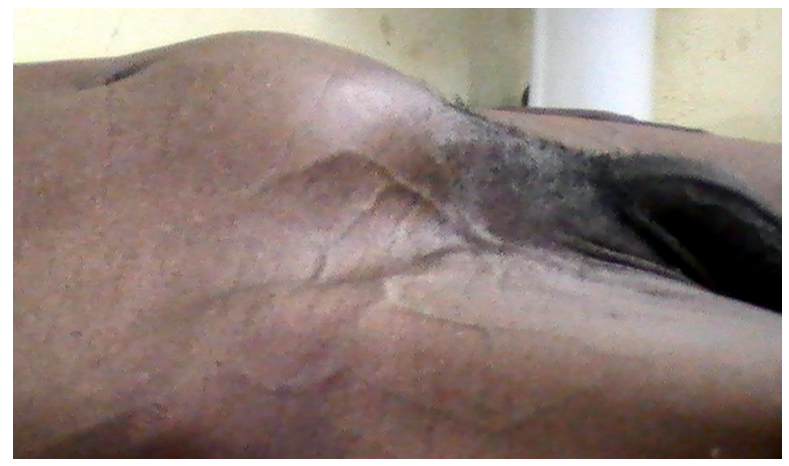

Figure 1. Bladder ball in a patient suffering from CAUR.

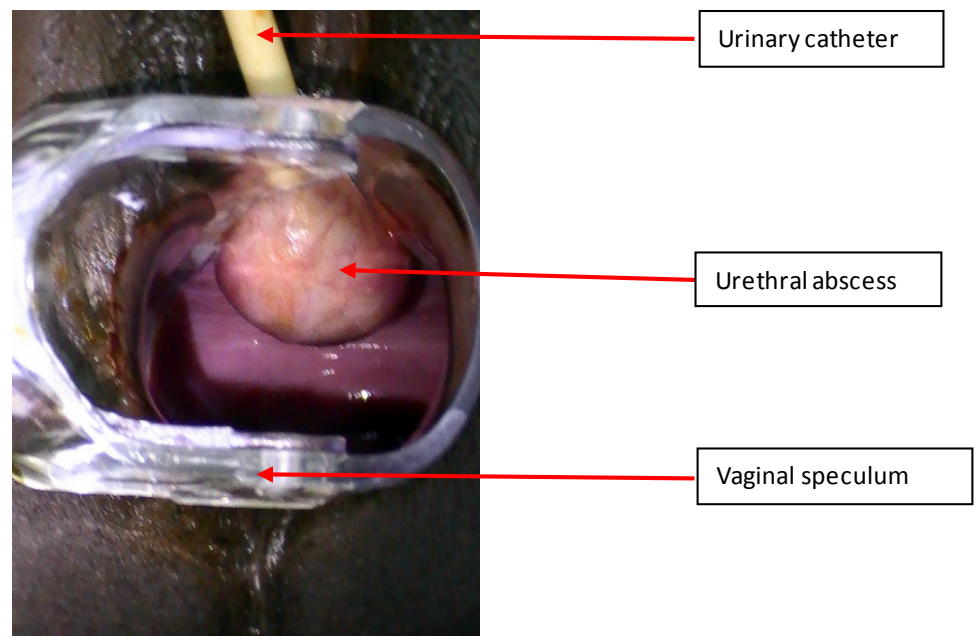

Figure 2. Urethral abscess, cause of a CAUR. 


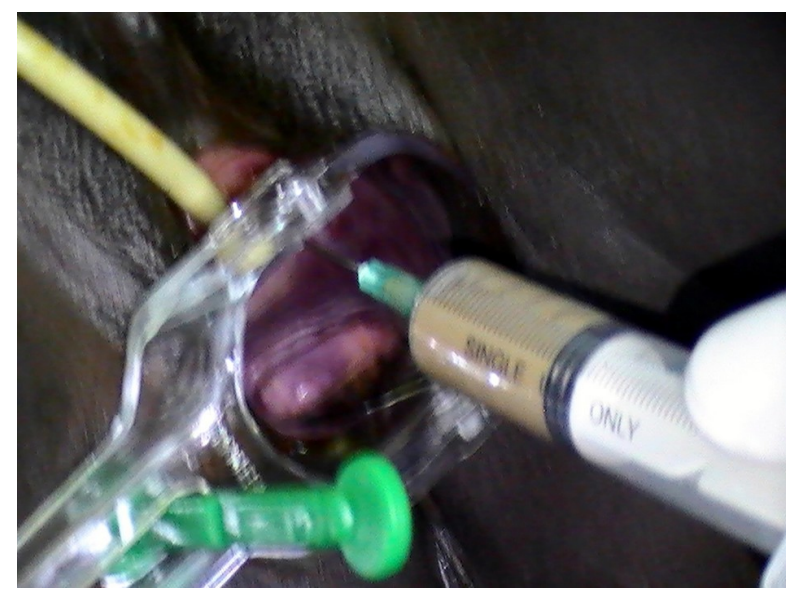

Figure 3. Puncture of a urethral abscess.

For the antecedent, we had: 49 cases of bladder cauterization, 30 cases of urine infections, one case of urological endoscopic management, 34 cases of pelvic surgery, 27 cases of pelvic trauma. The blood tests objectify: anemia in 61 patients. The rate of PSA was normal for 218 and high for 19 others, creatinine was up to $15 \mathrm{mg} / \mathrm{l}$ for 87 patients, 68 patients were diabetics. The X-Ray has objectified urethral strictures for 66 patients and the sonography indicated the augmentation of the Weight of the prostate in $95 \%$ of the patients who were more than 55 years old.

Management: 374 (61.71\%) urgent bladder catheterization, 139 suprapubic bladder puncture to evacuate urine and 93 cases of open bladder surgery after failure of the 2 previous gestures. Figure 4 and Figure 5 reported the medical and surgical management and its results.

\section{Discussion}

From 2008 to 2010, 1498 patients were consulted in urology department for various pathologies, 606 (40.45\%) suffered from CAUR. The CAUR was the first motive of consultation in urology department. The frequency of CAUR varied from $31 \%$ to $90 \%$ in studies around the world [6]-[11]. The high level of the frequency of the CAUR in Africa is the best testimony that people consult late for the lower urinary tract symptoms (LUTS). People behaviors can only be changed by information and sensitization. In our point of view, the CAUR must be considered as a later indicator of the urological consultation. In Africa in general and particularly in Chad, people did not consult earlier for this disease which concerned the external genitalia because it was a taboo around. The pathogenicity of CAUR is not unequivocal. It varies according to etiologies. Obstruction of the urethra when etiology is urethral stricture or $\mathrm{BPH}$; bladder compression for hematocolpos; inflammation for urine infection... The BPH was the first cause of CAUR in male particularly for those who were more than 60 years old [12] [13] [14]. Unperforated Hymen was the first cause of CAUR in the girls. Those girls were about 16 and 18 years old but they do not have their menarche because the menstruation was collected in the vaginal cavity due to the unperforated 


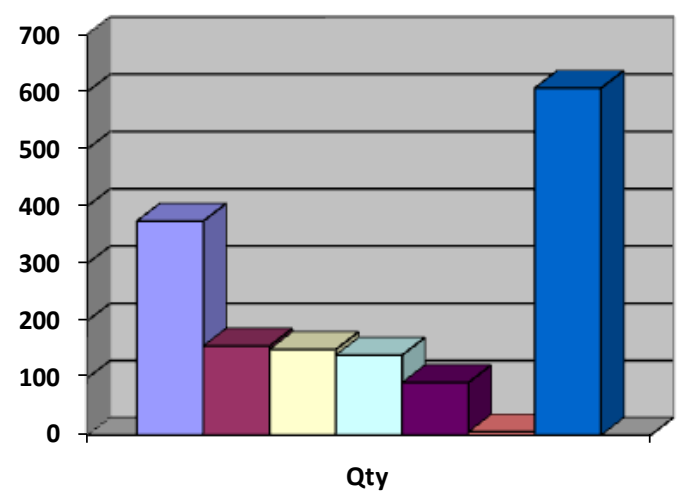

Figure 4. Distribution based on emergency gesture.

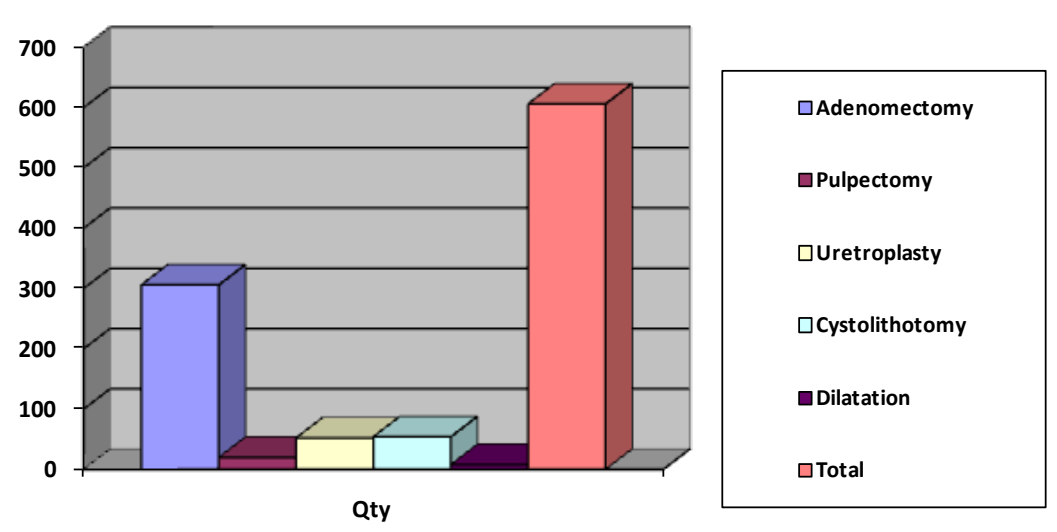

Figure 5. Distribution based on the surgery treatment.

hymen and constituted hematocolpos. The compression of the bladder by the volume of the hematocolpos was the reason of the CAUR for those young girls. A simple gynecology exam was the key of the diagnosis and the cross incision of the hymen is the main solution to bring out the menstruation and to restore the urine flux. Male urethral is longer than that of women urethral which exposes the men to more risk of lesions which finally gave CAUR. Some patient had urine infection few years before.

In spite of its etiology, the first and urgent gesture was the early evacuation of the urine from the bladder before doing the radical management which depends on the etiology.

\section{Conclusion}

In Chad, no data on CAUR were available before this study. The CAUR diagnosis is essentially clinical. The bladder globe is an evident physical sign. The aggravating factors were: male sex, age, infection antecedents, and bilharzia. Men were more victimized. The main etiologies were: $\mathrm{BPH}$, urethral strictures, lithiasis, and unperforated hymen from young girls. The emergency gesture was the evacuation of the bladder urine. The effective management depended on the etiology. The prevention of urinary infections and the rapid management of $\mathrm{BPH}$ were the best contribution in order to reduce the CAUR frequency. 


\section{References}

[1] Patoulias, I., Prodromou, K., Kallergis, K. and Koutsoumis, G. (2013) Acute Urinary Retention Due to Hematocolpos: Report of Two Cases. Journal of Pediatric Surgery Case Reports, 1, 189-191. https://doi.org/10.1016/j.epsc.2013.05.016

[2] Coulibaly, N., Dje, K., Yao, B., Akassimadou, N. and Bogni, L.P. (2013) Rétention aiguë d'urines sur vessie ptoséepost-traumatique: A propos d'uneobservation et revue de la littérature. JCC Open, 1, 41-43. https://doi.org/10.1016/j.jcco.2013.10.004

[3] Rizvi, R.M., Khan, Z.S. and Khan, Z. (2005) Diagnosis and Management of Postpartum Urinary Retention. International Journal of Gynecology and Obstetrics, 91, 71-72. https://doi.org/10.1016/j.ijgo.2005.06.025

[4] Boissier, R. (2012) Prise en charge d'une rétention aiguë d'urine. Journal Européen des Urgences et de Réanimation, 24, 78-85. https://doi.org/10.1016/j.jeurea.2012.04.001

[5] National Clinical Guideline Centre (UK) (2010) The Management of Lower Urinary Tract Symptoms in Men. Royal College of Physicians (UK), London. (NICE Clinical Guidelines, No. 97.) 4, Diagnosis. https://www.ncbi.nlm.nih.gov/books/NBK65072/

[6] Pickard, R., Emberton, M. and Neal, D. (1998) On Behalf of the National Prostatectomy Audit Steering Group. The Management of Men with Acute Urinary Retention. British Journal of Urology, 81, 712-720. https://doi.org/10.1046/j.1464-410x.1998.00632.x

[7] Park, K., Kim, S.H., Ahn, S.G., Lee, S.J., Ha, U.S., Koh, J.S., et al. (2012) Analysis of the Treatment of Two Types of Acute Urinary Retention. Korean Journal of Urology, 53, 843-847. https://doi.org/10.4111/kju.2012.53.12.843

[8] Wong, M.Y.C., Lim, Y.L. and Foo, K.T. (1994) Transurethral Resection of the Prostate for Benign Prostatic Hyperplasia-A Local Review. Singapore Medical Journal, 35, 357-359.

[9] Toure, C.T. and Dieng, M. (2002) Urgences en milieu tropical: État des lieux. L'exemple des urgences chirurgicales au Sénégal. Med Trop, 62, 237-241.

[10] Ahmed Gadam, I., Nuhu, A. and Aliyu, S. (2012) Ten-Year Experience with Open Prostatectomy in Maiduguri. ISRN Urology, 2012, Article ID: 406872.

[11] Hill, A.G. and Njoroge, P. (2002) Suprapubic Transvesical Prostatectomy in a Rural Kenyan Hospital. East African Medical Journal, 79, 65-67. https://doi.org/10.4314/eamj.v79i2.8902

[12] Fall, P.A., Gueye, S.M., Ndoye, A.K., Diao, D., Thiam, O.B.K., Abdallahi, M.O.C., et al. (2002) Mortalité et Morbidité précoces après adénomectomie prostatique par voie transvésicale. African Journal of Urology, 8, 20-23.

[13] Zango, B., Kambou, T. and Sanou, A. (2002) La résection transurétrale de la prostate à l'hôpital Sanou Souro de Bobo-Dioulasso: A propos de 68 cas. African Journal of Urology, 8, 1-5.

[14] Kambou, T., Zango, B., Ekoue, F., Traore, A.C., Bonkoungou, B., Ouattara, T. and Sano, D. (2006) Traitement chirurgical de l'hypertrophie bénigne de la prostate: Au $\mathrm{CHU}$ sanou souro de bobo-dioulasso (Burkina Faso) résultats à court et moyen terme-A propos de 190 cas. Médecine d Afrique Noire, 53, 605-612. 
Submit or recommend next manuscript to SCIRP and we will provide best service for you:

Accepting pre-submission inquiries through Email, Facebook, LinkedIn, Twitter, etc. A wide selection of journals (inclusive of 9 subjects, more than 200 journals)

Providing 24-hour high-quality service

User-friendly online submission system

Fair and swift peer-review system

Efficient typesetting and proofreading procedure

Display of the result of downloads and visits, as well as the number of cited articles Maximum dissemination of your research work

Submit your manuscript at: http://papersubmission.scirp.org/

Or contact oju@scirp.org 